\title{
Application of Gas Chromatography to Determination of Total Organic Fluorine after Defluorination of Perfluorooctanoic Acid as a Model Compound ${ }^{\dagger}$
}

\author{
Mariusz Koc, ${ }^{\text {a }}$ Magdalena Anna Donten, ${ }^{\text {a Jacek Musijowski, }},{ }^{a}$ Xinghua Guo, ${ }^{b}$ \\ Alexander Fauland, ${ }^{\mathrm{b}}$ Ernst Lankmayr, ${ }^{\mathrm{b}}$ and Marek Trojanowicz ${ }^{\mathrm{a}, *}$ \\ a Department of Chemistry, University of Warsaw, Pasteura 1, 02-093 Warsaw, Poland \\ ${ }^{\mathrm{b}}$ Institute of Analytical Chemistry and Food Chemistry, Graz University of Technology, Graz, Austria
}

RECEIVED NOVEMBER 11, 2010; REVISED MAY 12, 2011; ACCEPTED MAY 13, 2011

\begin{abstract}
Because of the global presence of anthropogenic perfluorinated organic compounds in the environment, foods and living organisms, and their large structural variety, it can be helpful to develop a method for determination of their total content at trace level in different matrices. In the developed method, the defluorination was carried with sodium biphenyl, derivatization of released fluoride to triphenylfluorosilane and determination by gas chromatography. Three detection methods were compared: flameionization detection, electron capture detection and mass spectrometry. Among them the MS detection was found to be the most favorable one in terms of the instrumental limit of detection (LOD), whereas the flame-ionization detection was considered to be the most favorable in terms of the method limit of detection (MDL). For the initial sample volume of $1 \mathrm{~L}$ and performing the whole procedure of determination, including preconcentration, the MDL value for perfluorooctanoic acid was evaluated as $0.043 \mathrm{ppb}$. (doi: $10.5562 /$ cca1798)
\end{abstract}

Keywords: perfluorinated organic compounds, surfactants, gas chromatography, total organic fluorine

\section{INTRODUCTION}

The wide interest observed in the recent decades in the presence of fluorinated organic compounds in the environment has different reasons and implications for the alteration of various technologies, modification of nutritional requirements, and diagnosis of some animal and human diseases. Among commonly known reasons of this interest one can indicate e.g. problem of emission of freons to the atmosphere, significant impact of fluoride ion on human health, and in the last decade the problem of global proliferation of perfluorinated organic compounds. Although the presence of those fully anthropogenic substances in human organisms was discovered at the end 1960s, only the studies conducted since 1990s proved their global presence in environment and living organisms including most remote regions..$^{1-4}$ Since this discovery, very intense analytical, ecological and toxicological studies were undertaken on their determination in various materials, ways of their distribution in environment, their stability in environment, and also on their interactions with living organisms. ${ }^{5}$ Among large number of different fluorinated substances identified in the environmental samples and living organisms several groups of compounds predominate, e.g. perfluorinated carboxylic and sulfonic acids, sulfonamides, and fluorotelomer alcohols.

Due to a large number of environmentally occurring compounds, their difficult identification and determination at ultra-trace level, some attempts are focused on the determination of their total content. Reportedly, so far in the analytical literature, attempts on determination of the Total Organic Fluorine (TOF) follow two basic steps - release fluorine from organic compounds and determination of fluorine as fluoride ion employing different analytical methods. In the proposed procedures of the TOF determination defluorination step is carried out by combustion in oxygen in $900-1000{ }^{\circ} \mathrm{C},{ }^{6,7}$ or by chemical reaction with sodium biphenyl reagent (SBP) ${ }^{8-10}$ Then the released fluoride are determined with ion-chromatography, ${ }^{6,7}$ by the flow-injection analysis (FIA) with potentiometric $\left(\mathrm{LOD}=103 \mu \mathrm{g} \mathrm{L}^{-1}\right)^{8}$ or fluorescence ${ }^{9}$ detections, or after the transformation to triphenylfluorosilane (TPSiF) by revered-phase high performance liquid chromatography (RP-HPLC) with UV detection. ${ }^{10}$ The reported FIA methods had insufficient

\footnotetext{
$\uparrow$ Presented at the $10^{\text {th }}$ International Symposium and Summer School on Bioanalysis within the CEEPUS Network CII-HU-001004-0910, Zagreb, Croatia, July 2010.

* Author to whom correspondence should be addressed. (E-mail: trojan@chem.uw.edu.pl)
} 
limits of detection, while the combustion ion-chromatography (CIC) method ${ }^{6,7}$ and the HPLC with effective preconcentration ${ }^{10}$ were satisfactory for analysis of the environmental samples. For such determinations, the gas chromatography (GC) has not been employed as a method for determination of fluoride, as yet.

The GC, commonly used in various areas of routine analytical chemistry, has already found numerous applications both for determination of fluoride as well as fluorinated organic compounds with various detection methods. GC determination of fluoride with flameionization detection (FID) were developed in 1960s with derivatization of fluoride ion to volatile triethylfluorosilane $^{11}$ or trimethylfluorosilane. ${ }^{12,13}$ The total content of fluorine in whole blood, serum/plasma and other biological samples was determined by GC using oxygen bomb combustion and reaction with triethylsilanol. ${ }^{14}$

In the GC determination of fluorinated organic compounds after suitable derivatization the electron capture detection (ECD) can be used, ${ }^{15,16}$ but as it was recently showed in the determination of perfluorinated carboxylic acids (PFCA) C6 to $\mathrm{C} 12$ after the derivatization with isobutyl chloroformate, evidently better values of the LOD can be obtained for the mass spectrometry (MS) detection with electron impact ionization, than the ECD. ${ }^{16}$ The GC measurements with various derivatization procedures is in fact the most frequently applied for this purpose. Without derivatization the GC was employed with chemical ionization in the determination of perfluorooctane sulfonate (PFOS) precursors and fluorotelomer alcohols, ${ }^{17}$ while with electron impact ionization in the determination of 8:2 telomer alcohol in animal plasma and tissues. ${ }^{18}$ Then with an appropriate derivatization and chemical ionization the GC/MS was used in the determination of PFCAs in aqueous matrices, ${ }^{19}$ and sediments, ${ }^{20}$ and also in isolating isomers of perfluorocarboxylates in polar bears. ${ }^{21}$

Recently in our research group we have developed a HPLC method as mentioned above for the determination of TOF, based on the transformation of fluoride into TPSiF. ${ }^{10}$ As this compound is volatile, although the separation requires a higher temperature than the earlier used trialkylfluorosilanes, ${ }^{12,14}$ it can be also determined by the GC with various detection methods. The aim of this work was to develop a GC method for the determination of TOF with the use of the earlier developed defluorination procedure with SBP and derivatization of fluoride to TPSiF. In order to optimize this method, the FID, ECD and MS detection have been compared.

\section{EXPERIMENTAL}

\section{Aparratus}

The chromatographic measurements were performed using: HP 5890 Series II GC with FID detector (system 1), HP 6890N GC with FID and ECD detectors (system 2), HP 6890S GC with 5973 MS detector (system 3), Hewlett Packard (Palo Alto, CA, USA) and GC-17A with MS QP-5000 (system 4) and QP-5050 (system 5) detectors (MS Shimadzu Kyoto, Japan).

The analytical columns used during measurements: HP-1 (100\% dimethylpolysiloxane), 30 m; 0.32 mm i.d.; $1 \mu \mathrm{m}$ film thickness, HP-5 (5\% phenyl $95 \%$ dimethylpolysiloxane) $30 \mathrm{~m}$; 0,25 mm i.d.; $0,25 \mu \mathrm{m}$ film thickness, Agilent J\&W GC Columns (Santa Clara, CA, USA) and ZB-5 (5\% phenyl $95 \%$ dimethylpolysiloxane) $30 \mathrm{~m}$; $0,25 \mathrm{~mm}$ i.d.; $0,25 \mu \mathrm{m}$ film thickness, Zebron (Torrance, CA, USA).

The Vortex mixer type 16700 was obtained from Thermolyne (Thermo, Waltham, MA, USA).

\section{Chemicals and Samples}

All chemicals used in the experiments were of analytical purity grade, unless specific purity is given. Diethyl ether, heptane, toluene and perchloric acid (70\%) were obtained from POCh (Gliwice, Poland), acetonitrile (gradient chromatography grade) was obtained from Merck (Darmstadt, Germany). Sodium fluoride ( $>99 \%$ ), triphenylsilyl fluoride (TPSiF) (97\%), triphenylsilanol (TPSiOH) (>98\%), perfluorooctanoic acid (PFOA, C8 PFCA), perfluorodecanoic acid (C10 PFCA) and sodium biphenyl (SBP) were obtained from SigmaAldrich (Steinheim, Germany).

Deionized water used throughout the experiments was obtained from Waters Milli-Q system (Waters, Bedford, MA, USA)

\section{Procedures}

The defluorination procedure of perfluorinated compounds was conducted as follows: approximately 10-20 $\mu \mathrm{L}$ of a given PFCA acetonitrile solution was mixed with $300 \mu \mathrm{L}$ of SBP in a $1.5 \mathrm{~mL}$ glass vial. The vial was kept closed for 10 minutes to conduct defluorination. Then, $500 \mu \mathrm{L}$ of water was added and the mixture was shaken vigorously. The organic layer was discarded and aqueous layer was washed once with $300 \mu \mathrm{L}$ of diethyl ether. $400 \mu \mathrm{L}$ of the aqueous phase containing fluoride was subjected to the derivatization procedure as described below.

The optimized procedure of fluoride derivatization was as follows: $400 \mu \mathrm{L}$ of aqueous fluoride solution of given concentration (water in case of blank) was placed in a $2 \mathrm{~mL}$ polypropylene Eppendorf-type test tube, mixed with $600 \mu \mathrm{L}$ of concentrated perchloric acid and $50 \mu \mathrm{L}$ of TPSiOH (typically $0.015 \mathrm{~mol} \mathrm{~L}^{-1}$ acetonitrile solution added for fluoride concentration range of 0.25

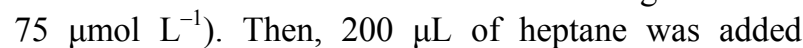
to the mixture and the tube was vigorously agitated using the vortex for approximately 60 minutes at room 

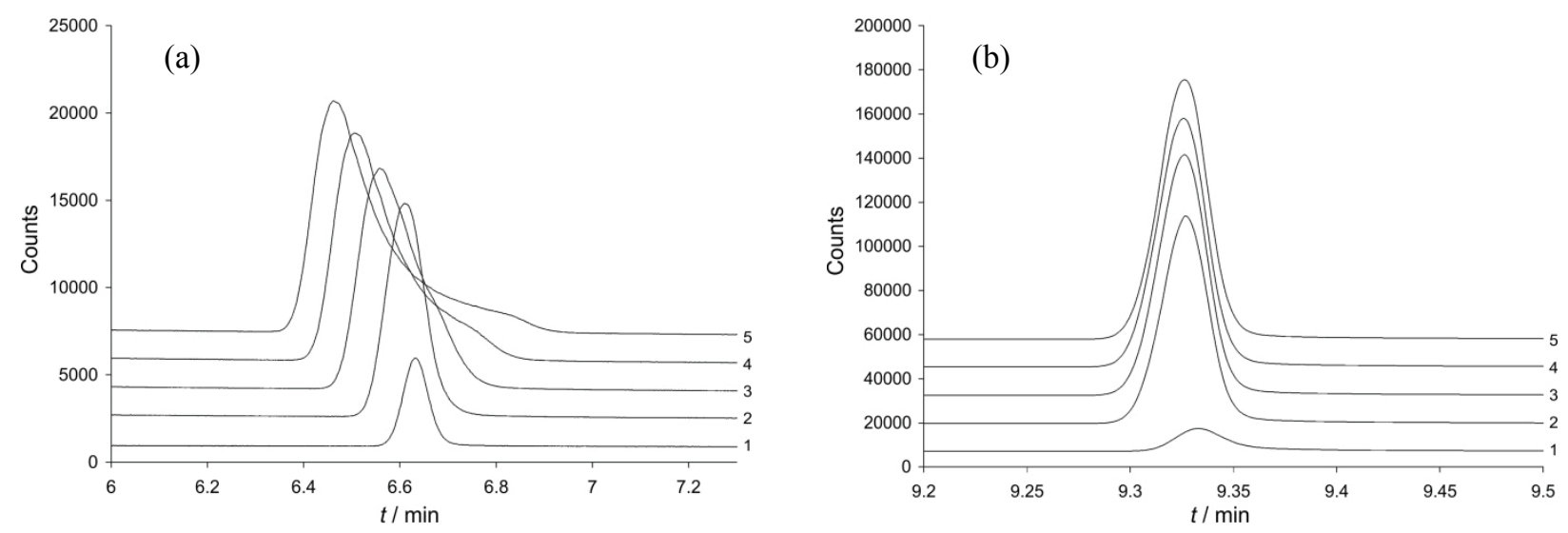

Figure 1. Chromatograms obtained in GC/FID system HP 5890 (system 1) with HP-1 column for $100 \mu \mathrm{mol} \mathrm{L}^{-1} \mathrm{TPSiF}_{\text {solution in }}$ heptane for different modes of injection in isothermal conditions at $225^{\circ} \mathrm{C}$ (a) and with temperature gradient conditions (b). Sample injection volume $2 \mu \mathrm{L}$. In (a): split injection (1), and splitless injection with split closure time 0.1 (2), 0.2 (3), 0.3 (4) and 0.4 (5) min. In (b) temperature gradient program $40{ }^{\circ} \mathrm{C}$ for $0.5 \mathrm{~min}, 40-250{ }^{\circ} \mathrm{C}$ with $30^{\circ} \mathrm{C} \mathrm{min}{ }^{-1} \mathrm{ramp}, 250{ }^{\circ} \mathrm{C}$ for $7.5 \mathrm{~min}$; split injection (1), and splitless injection with split closure time 0.1 (2), 0.2 (3), 0.3 (4) and $0.4(5)$ min. Injection at $325^{\circ} \mathrm{C}$, detection at $325^{\circ} \mathrm{C}$.

temperature. Finally, $100 \mu \mathrm{L}$ of heptane layer was aspirated and subjected to the GC measurement.

The chromatographic analysis was performed using HP 5890 Series II with FID detector (system 1) and GC-17A with MS QP-5000 (EI) detector (system 4) on HP-1 column with helium as the carrier gas and the flow rate of $30 \mathrm{~cm} \mathrm{~s}^{-1}$. Split injection was carried out with ratio $1: 20$. Splitless injection $(2 \mu \mathrm{L}, 0.2 \mathrm{~min})$ were performed at an initial oven temperature $40{ }^{\circ} \mathrm{C}$ for 0.5 min, ramped at $30^{\circ} \mathrm{C} \min ^{-1}$ to $250^{\circ} \mathrm{C}$ and hold $7.5 \mathrm{~min}$. Injector temperature was $325^{\circ} \mathrm{C}$. In case of FID detector temperature was $325^{\circ} \mathrm{C}$ and the flow rate of hydrogen

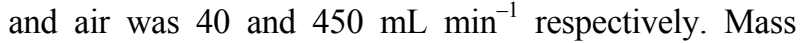
spectra were recorded across the range of $40-700 \mathrm{~m} / \mathrm{z}$ and for SIM mode $m / z$ 154, 201 and 278 were selected.

The chromatographic analysis also was performed using GC-17A with MS QP-5050 (EI) detector (system 5) on HP-5 column with helium as the carrier gas and the flow rate of $30 \mathrm{~cm} \mathrm{~s}^{-1}$. Splitless injection (1 $\mu \mathrm{L}, 0.2 \mathrm{~min}$ ) were performed at an initial oven temperature $40{ }^{\circ} \mathrm{C}$ for $0.5 \mathrm{~min}$, ramped at $30{ }^{\circ} \mathrm{C} \mathrm{min}^{-1}$ to $250{ }^{\circ} \mathrm{C}$ and hold $7.5 \mathrm{~min}$. Injector temperature was $325^{\circ} \mathrm{C}$. Mass spectra were recorded across the range of 40-700 $\mathrm{m} / \mathrm{z}$ and for SIM mode 154, 201 and $278 \mathrm{~m} / \mathrm{z}$ were selected.

The chromatographic analysis was performed using HP 6890N with FID and ECD detectors (system 2) and HP 6890S with MS (EI) detector (system 3) on $\mathrm{ZB}-5$ column with helium as the carrier gas and $30 \mathrm{~cm} \mathrm{~s}^{-1}$ flow rate. Splitless injection $(1 \mu \mathrm{L}, 0.6 \mathrm{~min})$ were performed at an initial oven temperature $40{ }^{\circ} \mathrm{C}$ for $2 \mathrm{~min}$, ramped at $40{ }^{\circ} \mathrm{C} \mathrm{min}^{-1}$ to $180{ }^{\circ} \mathrm{C}$ hold $0.5 \mathrm{~min}$, subsequently ramped at $10{ }^{\circ} \mathrm{C} \mathrm{min}^{-1}$ to $280{ }^{\circ} \mathrm{C}$ followed by $2 \mathrm{~min}$ hold. The injector temperature was $290{ }^{\circ} \mathrm{C}$. In case of FID detector temperature was $280{ }^{\circ} \mathrm{C}$ and $290{ }^{\circ} \mathrm{C}$ in case of ECD detector and the flow rate of hydrogen and air was 40 and $450 \mathrm{~mL} \mathrm{~min}^{-1}$ respectively for both. Mass spectra were recorded across the range of $40-700 \mathrm{~m} / \mathrm{z}$ and for SIM mode 154, 201 and $278 \mathrm{~m} / \mathrm{z}$ were selected.

\section{RESULTS AND DISCUSSION}

\section{Optimization of Chromatographic Conditions}

As method for the TOF determination should allow the analysis of trace level of perfluorinated compounds in different matrices, the main parameter for the optimization should be LOD and a satisfactory separation of TPSiF signal from the other solutes, which may result from a defluorination or derivatization procedure of fluoride ion. The initial measurements for the standard TPSiF solutions in heptane were carried with the FID detection (system 1) and with column Agilent J\&W HP-1. To obtain a satisfactory sensitivity of measurements, a significant factor is the mode of sample introduction, hence the signal magnitude was examined using splitless injection for different periods of closure time of the splitting ( 0.1 to $0.5 \mathrm{~min})$. In the isothermal conditions of separation at $225{ }^{\circ} \mathrm{C}$, for splitting closed for $0.1 \mathrm{~min}$ almost twice increase of signal was noticed in comparison to injection with open splitting, while the prolongation of closure of splitting practically does not influence the signal magnitude, and deteriorate the peak shape (Figure 1a).

Another important factor affecting the signal magnitude is the employed temperature program for chromatographic run. The most favorable results were obtained for introduction of the sample to the capillary column at $40{ }^{\circ} \mathrm{C}$, and after $0.5 \mathrm{~min}$ the possible quickest temperature increase was employed up to $250{ }^{\circ} \mathrm{C}$, in order to obtain the shortest possible retention time for TPSiF. The final temperature was achieved after $8.8 \mathrm{~min}$, 


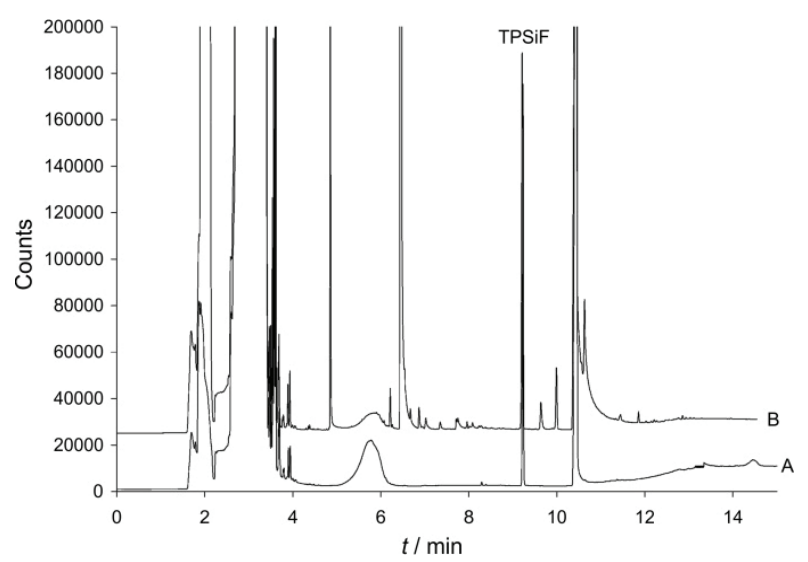

Figure 2. Comparison of chromatograms recorded for 75 $\mu \mathrm{mol} \mathrm{L}{ }^{-1}$ fluoride solution after derivatization (A) and for 125 $\mu \mathrm{mol} \mathrm{L}{ }^{-1}$ C8 PFCA (PFOA) solution after defluorination and derivatization (B). Conditions: GC/FID system HP 5890 (system 1) with HP-1 column, sample injection volume $2 \mu \mathrm{L}$, splitless injection with split closure time $0.2 \mathrm{~min}$, temperature gradient program $40{ }^{\circ} \mathrm{C}$ for $0.5 \mathrm{~min}, 40-250{ }^{\circ} \mathrm{C}$ with $30^{\circ} \mathrm{C} \mathrm{min}{ }^{-1}$ ramp, $250^{\circ} \mathrm{C}$ for $7.5 \mathrm{~min}$, injection at $325^{\circ} \mathrm{C}$, detection at $325^{\circ} \mathrm{C}$.

while the retention time for TPSiF in these conditions was $9.3 \mathrm{~min}$. For the samples analyzed after the complete procedure of defluorination with SBP and derivatization to TPSiF, in order to elute all the other present components the time of chromatographic run was 15 min. For such a temperature gradient the injection conditions were also optimized. As it is showed in Figure $1 \mathrm{~b}$, the optimum time for closing splitting was 0.2 min, where TPSiF signal was 20 times higher than for injection with splitting.

In such conditions, with $2 \mu 1$ injected sample volume, the calibration for TFSiF was made in the concentration range 0.1 to $75 \mu \mathrm{mol} \mathrm{L} \mathrm{L}^{-1}$. In the whole range a satisfactory linearity of response was obtained with precision not worse than $5 \% \mathrm{RSD}$. For $\mathrm{S} / \mathrm{N}=3$ the instrumental LOD was evaluated as $0.02 \mu \mathrm{mol} \mathrm{L} \mathrm{L}^{-1}$.

\section{Conditions of Defluorination and Derivatization of Fluoride Ions}

In order to release fluorine from the examined model of perfluorinated carboxylic acids for the TOF determination, the reactions with SBP or with persulfate radicals enhanced with microwave irradiation were employed.

The first one was optimized earlier for the HPLC determinations, ${ }^{10}$ and the earlier developed procedure was employed in this work for $\mathrm{C} 8, \mathrm{C} 10$ and $\mathrm{C} 12$ PFCAs. In the present GC determinations for SBP reaction $300 \mu \mathrm{l}$ volume of reagent was applied, which was a compromise between obtained yield of defluorination and blank signal, resulting from trace contamination of commercial SBP reagent with fluoride reported earlier. ${ }^{10}$ The examination of effect of the temperature for carrying the reaction with SBP in the range $20-40{ }^{\circ} \mathrm{C}$, as well as the time of its duration from 10 to $60 \mathrm{~min}$ has not showed influence of these factors on the reaction yield. Also the solvent used for PFCAs for defluorination (acetonitrile, toluene and diethyl ether) had no effect on the defluorination yield. Figure 2 shows chromatograms recorded in the GC/FID system (system 1) for $75 \mu \mathrm{mol} \mathrm{L} \mathrm{L}^{-1}$ fluoride solution after derivatization, and for $125 \mu \mathrm{mol} \mathrm{L} \mathrm{L}^{-1}$ solution of C8 PFCA (PFOA) after defluorination with SBP and derivatization of fluoride to TPSiF. One can see in both chromatograms that TPSiF signal is well resolved from all interferences from both steps of the applied procedures.

As it has recently been reported ${ }^{21}$ the efficient method of defluorination of PFCAs in aqueous solution can be the reaction with microwave-induced persulfate. It was confirmed also in this study for the decomposition of the PFOA solution at submillimolar solutions by carrying decomposition process at $160{ }^{\circ} \mathrm{C}$ by $60 \mathrm{~min}$. The recovery calculated based on the determined fluoride ion concentration was above $80 \%$. Due to the necessary step of PFCs preconcentration for trace level of determined analytes and elution with acetonitrile, similar process was examined in acetonitrile solutions. Due to scavenging of persulfate radicals by acetonitrile the yield of decomposition in acetonitrile was less than $55 \%$, hence this method was not used in further experiments.

The derivatization of fluoride with TPSiOH is carried out in strong acidic conditions. In our recent work ${ }^{10}$ we reported the optimization of kind of acids used, concentration of acid, taken volume of derivatizing reagent TPSiOH solution, reaction time and type of solvent used for extraction of derivatization product. First four of the mentioned parameters are independent of the detection method used for determination of TPSiF and can be identical for HPLC and GC determination. Regarding solvent taken for the extraction for HPLC heptane was selected due to a low absorption of UV radiation as compared to toluene and benzene, used earlier in the GC determinations. ${ }^{12}$ In this work we did not consider benzene due to its toxicity and the optimization was carried out for heptane and toluene. Figure 3 shows results obtained for the yield of derivatization conditions. Also in this case as an optimum solvent heptane was selected, which for 60 min derivatization time in ambient temperature allows to obtain a satisfactory yield of derivatization.

The optimized procedure of derivatization was employed for calibration with fluoride in concentration range from 0.2 to $80 \mu \mathrm{mol} \mathrm{L}^{-1}$ in the initial solution. In whole range the obtained calibration was linear with correlation coefficient 0.9999 and precision not worse than $5 \%$ RSD. The blank in such a procedure was evaluated as $0.15 \mu \mathrm{mol} \mathrm{L}^{-1}$ fluoride, and its main source is fluoride contamination is concentrated perchloric acid. Obviously, it is only a part of the total blank for complete procedure in TOF determination. 


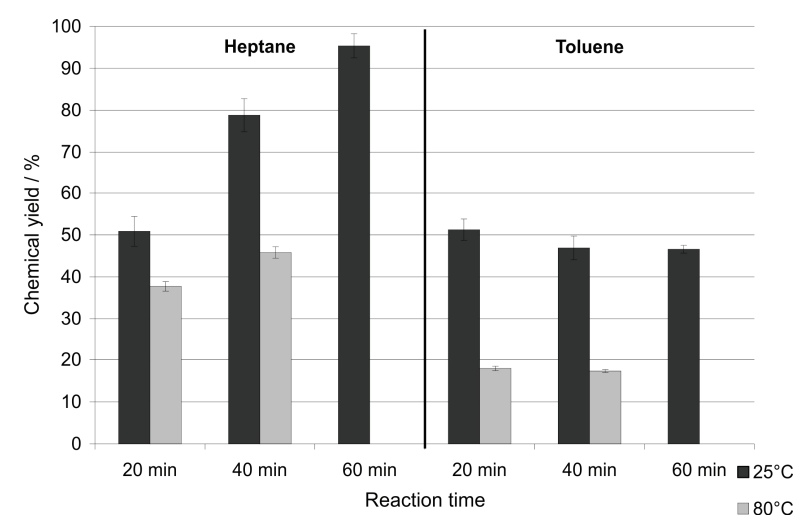

Figure 3. Effect of solvent used, used time of reaction, and temperature on yield of derivatization of fluoride solution $\left(c=10 \mu \mathrm{mol} \mathrm{L}{ }^{-1}\right)$ with TPSiOH.

Table 1. Instrumental LOD values obtained for determination of TPSiF and MDL values obtained for fluoride ion involving the derivatization procedure for $\mathrm{GC}$ measurements with different detections for different columns

\begin{tabular}{|c|c|c|c|}
\hline \multirow{2}{*}{ Method } & \multirow{2}{*}{ Column } & \multirow{2}{*}{$\begin{array}{l}\text { Measuring } \\
\text { system }^{(a)}\end{array}$} & LOD (TPSiF) \\
\hline & & & $\mu \mathrm{mol} \mathrm{L}{ }^{-1}$ \\
\hline \multirow[t]{2}{*}{ FID } & HP-1 & System 1 & 0.02 \\
\hline & ZB-5 & System 2 & 0.08 \\
\hline ECD & ZB-5 & System 2 & 0.3 \\
\hline \multirow[t]{3}{*}{ MS } & HP-1 & System 4 & 0.1 \\
\hline & HP-5 & System 5 & 0.02 \\
\hline & ZB-5 & System 3 & 0.003 \\
\hline
\end{tabular}

${ }^{(a)}$ Numbering according to descriptions in experimental.

\section{Comparison of Detection Methods}

For the GC determination of TPSiF employed for determination of TOF, besides the FID detection, also the detection with ECD detector and the MS with electron impact ionization were investigated. Additionally for better illustration of the effect of different factors LOD values were determined in case of the FID and the MS detections using different measuring systems equipped with different columns, in order to examine how type of instrument may affect such determinations.

The values of limit of the detection were evaluated in two different meanings. The instrumental LOD value was evaluated taking into account the signal magnitude $\mathrm{S}$ for injected TPSiF solutions, and the noise amplitude $\mathrm{N}$ of the base-line. The LOD was calculated as a concentration corresponding to $\mathrm{S} / \mathrm{N}=3$. In this case one may expect that the LOD values significantly depend on an employed instrument, type of column, and conditions of chromatographic run. Some comparison of the obtained recording for three systems with the FID and the MS detectors are showed in Figure 4. The aim of presenting Figure 4 is to show the differences in signal to noise ratio, because it determines the instrumental LOD.

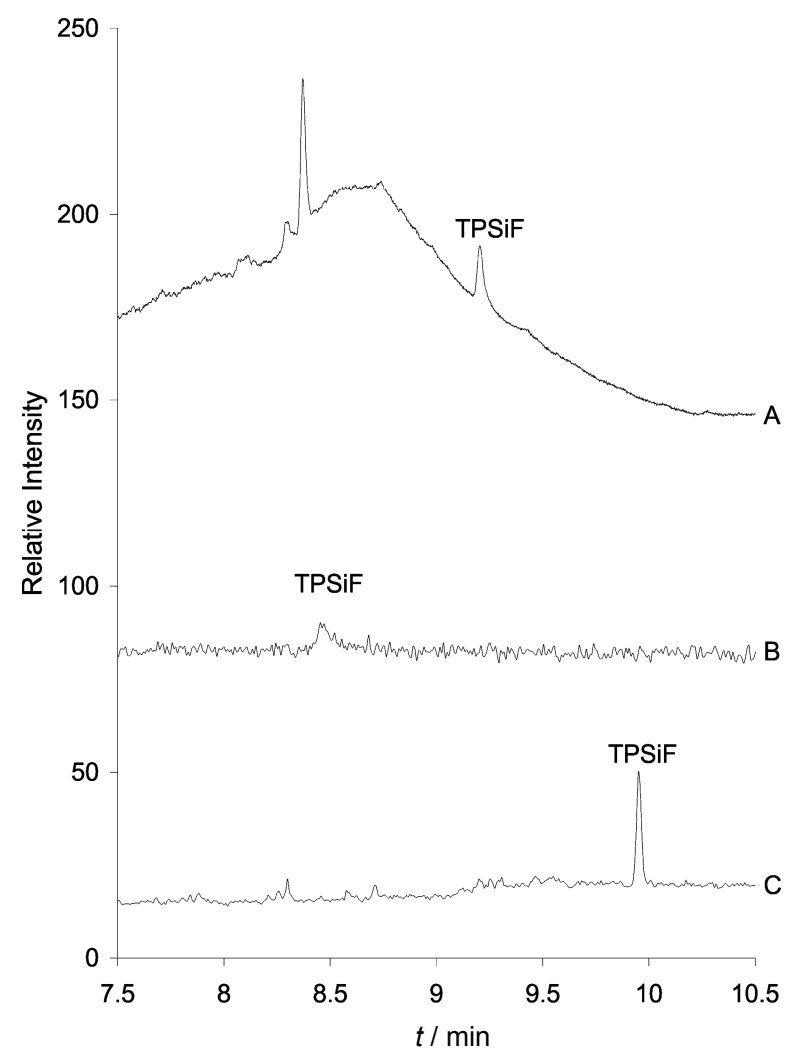

Figure 4. Chromatograms recorded in different GC systems for $0.1 \mu \mathrm{mol} \mathrm{L} \mathrm{L}^{-1}$ TPSiF solution in heptane: GC/FID system HP 5890 (system 1) with HP-1 column, sample injection volume $2 \mu \mathrm{L}$, splitless injection with split closure time $0.2 \mathrm{~min}$, temperature gradient program $40{ }^{\circ} \mathrm{C}$ for $0.5 \mathrm{~min}$, $40-250{ }^{\circ} \mathrm{C}$ with $30{ }^{\circ} \mathrm{C} \mathrm{min}^{-1} \mathrm{ramp}, 250{ }^{\circ} \mathrm{C}$ for $7.5 \mathrm{~min}$, injection at $325{ }^{\circ} \mathrm{C}$, detection at $325^{\circ} \mathrm{C}(\mathrm{A})$; GC/MS system QP5000 (system 4) with HP-1 column, SIM mode $m / z$ : 278, 201, 154 , sample injection volume $2 \mu \mathrm{L}$, splitless injection with split closure time $0.2 \mathrm{~min}$, temperature gradient program $40{ }^{\circ} \mathrm{C}$ for $0.5 \mathrm{~min}, 40-250{ }^{\circ} \mathrm{C}$ with $30^{\circ} \mathrm{C} \mathrm{min}{ }^{-1} \mathrm{ramp}, 250{ }^{\circ} \mathrm{C}$ for $7.5 \mathrm{~min}$, injection at $325^{\circ} \mathrm{C}(\mathrm{B})$; GC/MS system QP-5050 (system 5) with HP-5 column, SIM mode $m / z$ : 278, 201, 154, sample injection volume $1 \mu \mathrm{L}$, splitless injection with split closure time $0.2 \mathrm{~min}$, temperature gradient program $40{ }^{\circ} \mathrm{C}$ for $0.5 \mathrm{~min}, 40-250{ }^{\circ} \mathrm{C}$ with $30^{\circ} \mathrm{C} \min ^{-1} \mathrm{ramp}, 250{ }^{\circ} \mathrm{C}$ for 7.5 min, injection at $325^{\circ} \mathrm{C}(\mathrm{C})$.

Chromatogram B (system 4) has the smallest signal and the largest noise. Chromatogram A (system 1) has a smaller signal than the chromatogram $\mathrm{C}$, but it also has a smaller noise so in this case two particular systems with FID and MS Detections (system 1 and 5) exhibit the same LOD values. The MDL values were evaluated taking into account magnitude and precision of blank measurements, obtained for fluoride detection with derivatization, or for C8 PFCA used as model perfluorinated substance for TOF determination using complete procedure with defluorination and derivatization. Table 1 shows the obtained results of the instrumental LOD values for all configurations of the GC systems 

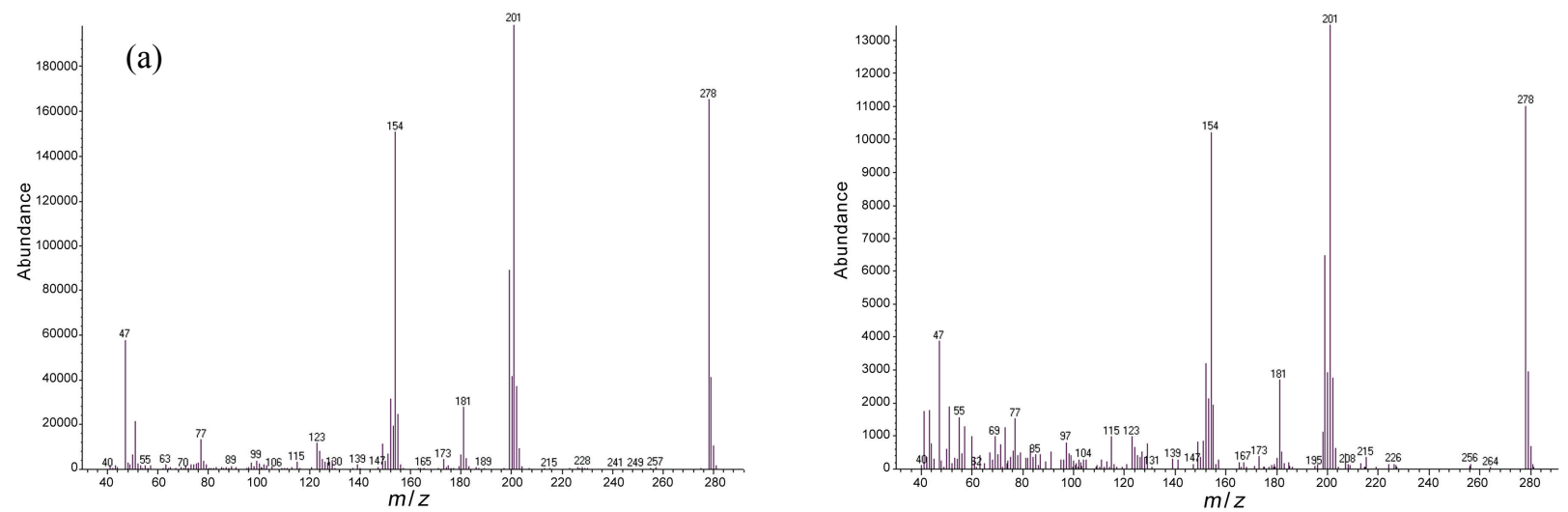

Figure 5. Mass spectra obtained from measurements in GC/MS system HP 6890S (system 3) with ZB-5 column for $1 \mu \mathrm{L}$ injection of $90 \mu \mathrm{mol} \mathrm{L}{ }^{-1}$ TPSiF solution in heptane (a), and for solution obtained after complete procedure of defluorination and derivatization carried out for $20 \mu \mathrm{L}$ of $7.7 \mu \mathrm{mol} \mathrm{L}{ }^{-1}$ solution of C8 PFCA (PFOA) (b). Conditions: splitless injection with split closure time $0.6 \mathrm{~min}$, temperature gradient program $40^{\circ} \mathrm{C}$ for $2 \mathrm{~min}, 40-180^{\circ} \mathrm{C}$ with $40{ }^{\circ} \mathrm{C} \mathrm{min}{ }^{-1} \mathrm{ramp}, 180{ }^{\circ} \mathrm{C}$ for $0.5 \mathrm{~min}, 180-280{ }^{\circ} \mathrm{C}$ with $10{ }^{\circ} \mathrm{C} \mathrm{m^{-1 }}$ ramp, $280{ }^{\circ} \mathrm{C}$ for $2 \mathrm{~min}$, injection at $290{ }^{\circ} \mathrm{C}, \mathrm{m} / \mathrm{z}$ range from 40 to 700 .

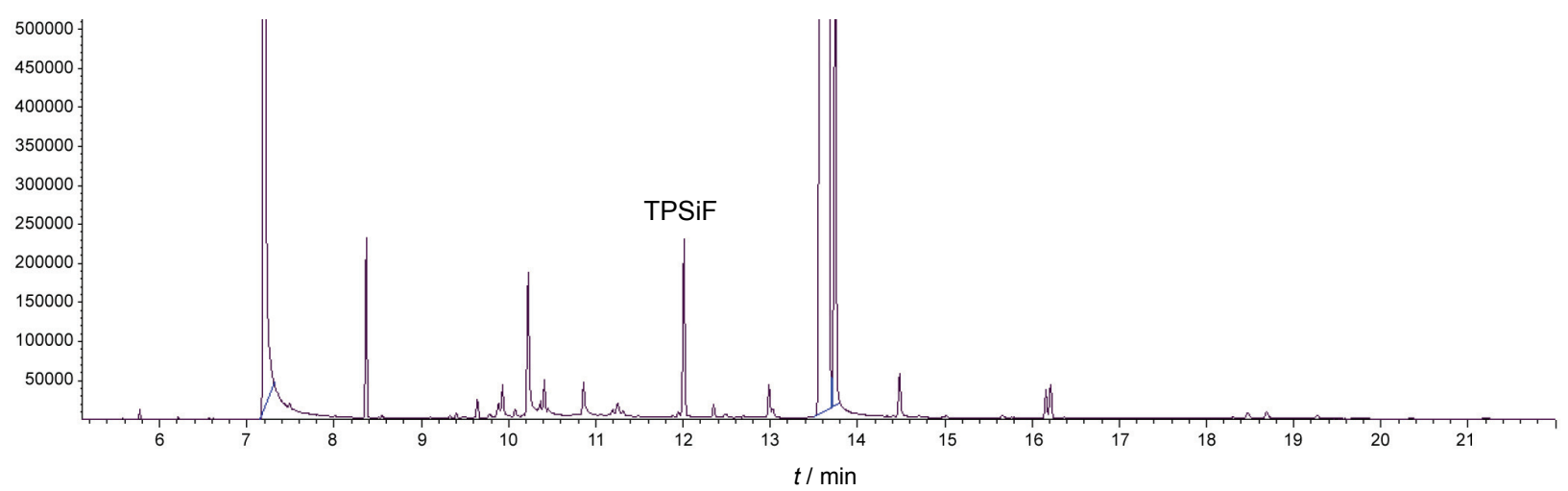

Figure 6. Chromatogram recorded in GC/MS system HP 6890S (system 3) with ZB-5 column for blank (20 $\mu$ L acetonitrile) after carrying the complete procedure of defluorination and derivatization. Conditions: sample injection volume $1 \mu \mathrm{L}$, splitless injection with split closure time $0.6 \mathrm{~min}$, temperature gradient program $40{ }^{\circ} \mathrm{C}$ for $2 \mathrm{~min}, 40-180{ }^{\circ} \mathrm{C}$ with $40{ }^{\circ} \mathrm{C} \mathrm{min}{ }^{-1} \mathrm{ramp}, 180^{\circ} \mathrm{C}$ for $0.5 \mathrm{~min}, 180-280^{\circ} \mathrm{C}$ with $10^{\circ} \mathrm{C} \mathrm{min}^{-1} \mathrm{ramp}, 280^{\circ} \mathrm{C}$ for $2 \mathrm{~min}$, injection at $290{ }^{\circ} \mathrm{C}$, SIM mode $\mathrm{m} / \mathrm{z}: 278,201,154$.

used. In comparison to the GC/FID system reported above, for the other one (system 2) used with ZB-5

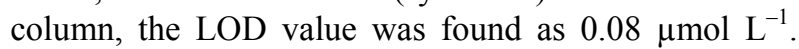
The observed difference resulted mostly from the different noise amplitude for both systems, regardless the column used.

The application in the same GC (system 2) setup with ZB-5 column of the ECD detector provides disappointing results. For such a system the poorest LOD value $0.3 \mu \mathrm{mol} \mathrm{L}{ }^{-1}$ was obtained with the worst efficiency of separation, which can be attributed probably to the presence of non-resolved halogenated organic contaminants for used solvents. The obtained calibration line also showed poorer linearity $\left(r^{2}=0.987\right)$ and precision in the range of 2.2 to $10.8 \%$ RSD for measured concentration range. The precision of the both GC/FID used was better than $3.0 \%$ RSD in whole concentration range.
Taking into account the earlier works on application of the GC in the determination of PFCs, the improvement of limit of the detection and the selectivity of determinations can be expected from application of the MS detection with electron impact ionization. Based on the mass spectra recorded for TPSiF solution in heptane (Figure 5a), which was in good agreement with spectrum from NIST catalogue, for examination of sensitivity of TPSiF determination three signals were used. Signal at $\mathrm{m} / \mathrm{z} 278$ corresponds to monovalent molecular ion, and signals for $\mathrm{m} / z 210$ and 154 result from fragmentation of TPSiF by subtraction of one or two phenyl groups. The LOD determined for total ion current (TIC) mode for TPSiF was $0.045 \mu \mathrm{mol} \mathrm{L}^{-1}$, while for single ion monitoring (SIM) mode calculated for sum of three mentioned ions was $0.003 \mu \mathrm{mol} \mathrm{L} \mathrm{L}^{-1}$, which is listed in Table 1. 
The recorded GC/MS (system 3) chromatogram of blank in the SIM mode showed in Figure 6 indicated from one side the selectivity and sensitivity of the GS/MS determination, but on another one a significant role of contamination in the blank for the TOF determination in whole procedure including defluorination and derivatization. For the illustration of possible application of MS detection for the determination of TOF, the mass spectrum for PFOA, after complete procedure of defluorination and derivatization, is showed in Figure 5b. The similarity of the both spectra showed in Figure 5 indicates the lack of evident interferences affecting the signal of analyte in such procedure. For these instrumental conditions the linearity of calibration curve was satisfactory $\left(r^{2}=0.9991\right)$, while precision of measurements was poorer than in measurements with FID detection (0.6-6.7 \% RSD).

Similar measurements were carried out with two other GC/MS instruments (system 5) equipped with HP5 MS column (nominally the same as ZB-5), and with HP-1 (system 4) of larger bore and thicker layer. In the system with HP-5 column (system 5) about 6-fold poorer LOD was observed for the SIM mode, while for HP-1 column, essentially not suitable for the MS detection, about 30 times worse LOD values were obtained. As it was mentioned (and illustrated in Figure 4) the main factor contributing to this effect is the base-line noise amplitude and conditions of chromatographic run. For comparison it can be admitted that instrumental LOD for the determination of TPSiF by HPLC with UV detection was $0.09 \mu \mathrm{mol} \mathrm{L}^{-1} .{ }^{10}$

In the determination of TOF with complex defluorination procedure the crucial factor for the MDL is the level of blank measured in each instrumental setup and precision of blank measurements from multiple repetitions of derivatization. Generally, it was observed that precision of TPSiF determination is much better for FID detectors $(0.2$ to $3.0 \%$ RSD). The MDL values were compared for system 1 and 3, exhibiting LOD values as shown in Table 1.

The best value of MDL for fluoride determination $0.4 \mu \mathrm{mol} \mathrm{L}^{-1}$ was obtained for system 1 with FID detector, while for the GC/MS instrument (system 3) the MDL was $1.3 \mu \mathrm{mol} \mathrm{L}^{-1}$ fluoride. The reason of this difference is evidently worse precision observed in measurements with the MS detection, exceeding in some cases even $10 \%$ RSD. The MDL in the GC/FID system is then practically the same as obtained for HPLC determinations with UV detection $0.36 \mu \mathrm{mol} \mathrm{L}^{-1},{ }^{10}$ and more favorable than measured for GC/MS measurements.

\section{GC Determination of TOF with Flame-Ionization Detection}

The possibility of TOF determination with developed the GC/FID method was examined for two model perfluorinated compounds C8 PFCA (PFOA) and C10
PFCA, which belong besides C9 PFCA to most commonly occurring PFCAs in environmental samples. ${ }^{4}$ The measuring system, with the use of complete procedure of defluorination and derivatization was calibrated using standard fluoride solutions in concentration range from 0.2 to $80 \mu \mathrm{mol} \mathrm{L}{ }^{-1}$ fluoride. Then the same measurements were performed with C8 and C10 PFCAs acetonitrile solutions in the concentration range from 3 to $133 \mu \mathrm{mol} \mathrm{L}^{-1}$ in $20 \mu \mathrm{L}$ sample volume taken for defluorination reaction with SBP and further derivatization. The signal values obtained in the GC/FID measurements allowed to get the linear calibration plots, with relative slope compared to fluoride plot 99.8 and $75.5 \%$ for C8 and C10 PFCAs, respectively. It means the obtaining a satisfactory recovery of whole procedure for given range of PFCAs concentrations.

The detection limits for C8 PFCA, for $20 \mu \mathrm{L}$ of solution taken for defluorination and derivatization was evaluated as $5.2 \mu \mathrm{mol} \mathrm{L}^{-1}$, however when it is taken as initial sample volume for preconcentration on carbon sorbent $1000 \mathrm{~mL},{ }^{10}$ and preconcentrated species will be eluted with acetonitrile and evaporated to obtain $20 \mu \mathrm{L}$ for further processing, the real MDL: value can be evaluated as $0.104 \mathrm{nmol} \mathrm{L}^{-1}$ (43 ppt), which means that the developed the GC/FID method for TOF determination can be employed for analysis of environmental samples.

\section{CONCLUSION}

The purpose of this article is to present the possibilities of the TOF determination with the equipment available in each laboratory (chemical defluorination with the SBP and determination by the GC) as an alternative to the CIC method. ${ }^{6,7}$ The reagent used for derivatization TPSiOH has a higher boiling point than the previously used reagents ${ }^{11-13}$ so it is easier to prepare the samples as well as conduct separation by GC with a suitable temperature program. The presence of three phenyl groups makes TPSiOH more universal as a derivatization reagent because the reaction product may be determined by the GC and the HPLC. Compared to the CIC method, and similarly do RP-HPLC with UV detection, present method is instrumentally simpler, as it does not require a combustion oven. In comparison of three different detection methods, for ECD the worst LOD values were observe. The best LOD value was found for the MS detection, but the MDL values were better for the GC system with FID detection. In the optimized conditions, taking into account the contamination of reagents and the reported earlier possibility of efficient preconcentration combined on activated carbon sorbents with separation of inorganic fluoride, the MDL value for C8 PFCA (PFOA) was evaluated as $0.104 \mathrm{nmol} \mathrm{L}^{-1}$ $(43 \mathrm{ppt})$, allowing the use of this method for the analysis of environmental samples. 
Further studies on this subject will be focused on examination of the developed method for different fluorinated organic analytes expected in environmental samples, and on the determination of TOF in real samples of natural surface waters.

Acknowledgements. The financial support for M. A. Donten and M. Koc for their study stays at Graz University of Technology, research group of Professor E. Lankmayr, by CEEPUS Program CII-HU-II is kindly acknowledged

\section{REFERENCES}

1. D. R. Taves, Nature 217 (1968) 1050-1051.

2. B. D. Key, R. D. Howell, and C. S. Criddle, Environ. Sci. Technol. 31 (1997) 2445-2454.

3. J. P. Giesy and K. Kannan, Environ. Sci. Technol. 35 (2001) 1339-1342.

4. K. Prevedouros, I. T. Cousins, R. C. Buck, and S. H. Korzeniowski, Environ. Sci. Technol. 40 (2006) 32-44.

5. Analysis of Fluorinated Surfactants in: E. Kissa (Ed.), Fluorinated Surfactants and Repellants. Chp. 9 Marcel Dekker, New York 2001, pp. 390-450.

6. Y. Miyake, N. Yamashita, M. K. So, P. Rostkowski, S. Taniyasu, P. K. S. Lam, and K. Kannan, J. Chromatogr., A 1154 (2007) 214-221.
7. Y. Miyake, N. Yamahsita, P. Rostkowski, M. K. So, S. Taniyasu, P. K. S. Lam, and K. Kannan, J. Chromatogr., A 1143 (2007) 98-104.

8. J. Musijowski, M. Trojanowicz, B. Szostek, J. L. Costa Lima, R. Lapa , H. Yamashita, T. Takayanagi, and S. Motomizu, Anal. Chim. Acta 600 (2007) 147-154.

9. T. Takyanagi, H. Yamashita, S. Motomizu, J. Musijowski, and M. Trojanowicz, Talanta 74 (2008) 1224-1230.

10. J. Musijowski, B. Szostek, M. Koc, and M. Trojanowicz, J. Sep .Sci. 33 (2010) 2636-2644.

11. R. Bock and H. J. Semmler, Z. Anal. Chem. 230 (1967) 161-184.

12. J. A. Fresen, F. H. Cox, and M. J. Witter, Pharm. Weekblad 103 (1968) 909-914.

13. J. H. Glerum, A. Van Dijk, and S. W. Klein, Pharm. Weekblad Sci. Ed. 6 (1984) 75-79.

14. J. Belisle and D. F. Hagen, Anal. Biochem. 87 (1978) 545-555.

15. J. Belisle and D. H. Hagen, Anal. Biochem. 101 (1980) 369-376.

16. V. Dufkova, R. Cabala, D. Maradova, and M. Sticha, J. Chromatogr., A 1216 (2009) 8659-8664.

17. J. W. Martin, D. C. G. Muir, C. A. Moody, D. A. Ellis, W. C. Kwan, K. R. Solomon, and S. A. Mabury, Anal. Chem. 74 (2002) 584-590.

18. B. Szostek and K. B. Prickett, J. Chromatogr., B: Anal. Technol. Biomed. Life Sci. 813 (2004) 313-321.

19. R. Alzaga and J. M. Bayona, J. Chromatogr., A 1042 (2004) 155-162.

20. R. Alzaga, C. Salgado-Petinal, E. Jover, and J. M. Bayona, J. Chromatogr., A 1083 (2005) 1-6.

21. Y. C. Lee, S. L. Lo, P. T. Chiueh, and D. G. Chang, Water Res. 43 (2009) 2811-2816. 